\title{
A Study on Relationships Among Self-esteem, Major Satisfaction, Social Support and College Life Adjustment of Nursing Students
}

\author{
Young-Ju Jee ${ }^{1}$ and Seung-Kyoung Yang ${ }^{2}$ \\ College of Nursing, Kyungnam University, Korea \\ ${ }^{1}$ jeeyoungju@kyungnam.ac.kr, ${ }^{2}$ yangsk@kyungnam.ac.kr
}

\begin{abstract}
This study was descriptive survey research to examine the relationships between selfesteem, major satisfaction, social support, and college life adjustment of nursing students. The subjects were 95 first-grade nursing students at a college located in $G$ city. The data collected by self-reported questionnaires were used to identify general characteristics, selfesteem, major satisfaction, social support, and college life adjustment. Data were analyzed using descriptive statistics, $t$-test, ANOVA, and Pearson's correlation coefficients in the SPSS statistics 20.0 program. The mean score of college life adjustment was $3.45 \pm 0.45$. College life adjustment was significantly positive correlation of self-esteem $(r=.661, p<.001)$, major satisfaction ( $r=.619, p<.001)$, social support $(r=.513, p<.001)$. Based on the results of this study, it is necessary to be considered self-esteem, major satisfaction, and social support during the development convergence intervention program to improve the college life adjustment of nursing students.
\end{abstract}

Keywords: Nursing students, College life adjustment, Self-esteem, Major satisfaction, Social support

\section{Introduction}

The college period is an important one to establish self-identity and lifestyle beyond adolescence. The students in this period have to solve various problems faced in the course of preparing as social members, which may lead to psychological burdens and adjustment difficulties [1]. Successful adjustment to college life has a positive effect such as enhancing academic achievement and positive peer relationships [2], however, failure in such adjustment may lead students to decide to leave school or drop out, ultimately to poor quality of life [3][4].

Nursing students, due to the nature of the nursing curriculum, experience considerable stress caused by an excessive amount of study and clinical practice, which may harm college life adjustment [5]. Since the correction of college life maladjustment becomes more difficult in the upper grades, it is important to manage the adjustment of college students from the early period so that they can cope with their difficulties by themselves [6][7].

The factors affecting college life adjustment include, according to previous studies include major satisfaction, the interaction between professors and students [8], social support, psychological health [9], and self-esteem [10]. The research on the adjustment of college students in nursing ones has been limited. It is necessary, therefore, to provide a systematic

Article history:

Received (March 25, 2019), Review Result (April 26, 2019), Accepted (May 27, 2019) 
way to help them to adapt to college life successfully. The purpose of this study was, therefore, to provide fundamental data to be used in developing intervention programs for the college life adjustment of 1st-grade students of the nursing college by investigating the relationship among college life adjustment and self-esteem, major satisfaction, and social support for them.

\section{Method}

\subsection{Design}

This descriptive research study intended to investigate the relationship between college life adjustment and self-esteem, major satisfaction, and social support for 1st-grade students of nursing college.

\subsection{Subjects}

The subjects were 95 1st-grade students in a nursing college located in G city and data were collected from 12th to 26th March 2019. Before data collection, the researcher explains the purpose and contents of the research and acquired written consent stating that they understand the research and agree to participate in the research. The self-report method using the structured questionnaire was conducted to collect data.

\subsection{Instrument}

The questionnaire consisted of items general characteristics, college life adjustment, selfesteem, major satisfaction, and social support. The college life adjustment was measured by using 34 items from General College Life Adjustment Scale developed by Park [11]. A higher score, on this scale, indicates better adjustment. Self-esteem was measured by an instrument composed of 10 items developed by Rosenberg [12] and translated by Jon [13] where a higher score indicates more judgment of him/herself as a valuable and satisfying person. The major satisfaction was measured by using 18 items from the instrument developed by Ha [14] and revised by Lee [15] where a higher score indicates higher satisfaction with the major, the social support was measured by using 25 items from the instrument developed by park [16] and revised by Kim [17] where a higher score indicates higher social support.

\subsection{Analysis}

The collected data were analyzed using the IBM SPSS 20.0 program. The general characteristics, college life adjustment, self-esteem, major satisfaction, and social support of subjects were analyzed using descriptive statistics. The differences in college life adjustment according to their general characteristics were analyzed using t-test and ANOVA. The correlations among college life adjustment, self-esteem, major satisfaction, and social support were analyzed using Pearson's correlation coefficient.

\section{Result}

\subsection{General characteristics}

The general characteristics of participants were shown in [Table 1]. $77.9 \%$ of the participants were female, $67.4 \%$ were no religion, and $47.4 \%$ thought that they had a good 
health state. $51.6 \%$ were in a medium economic state, $49.5 \%$ were living with parents, and $35.8 \%$ were the motivation for admission because of a high employment guarantee.

Table 1. General characteristics $(\mathrm{N}=95)$

\begin{tabular}{|c|c|c|}
\hline Characteristics & Categories & $\mathrm{n}(\%)$ or $\mathrm{M} \pm \mathrm{SD}$ \\
\hline \multirow{2}{*}{ Gender } & Male & $21(22.1)$ \\
\hline & Female & $74(77.9)$ \\
\hline Age(yr) & & $21.40 \pm 3.39$ \\
\hline \multirow{4}{*}{ Religion } & Christian & $12(12.6)$ \\
\hline & catholic & $4(4.2)$ \\
\hline & Buddhism & $15(15.8)$ \\
\hline & no religion & $64(67.4)$ \\
\hline \multirow{5}{*}{ Health state } & very good & $19(20.0)$ \\
\hline & good & $45(47.4)$ \\
\hline & moderate & $24(25.3)$ \\
\hline & bad & $5(5.3)$ \\
\hline & very bad & $2(2.1)$ \\
\hline \multirow{4}{*}{ Economic state } & very high & $9(9.5)$ \\
\hline & high & $23(23.2)$ \\
\hline & medium & $49(51.6)$ \\
\hline & low & $15(15.2)$ \\
\hline \multirow{4}{*}{ Residential type } & dormitory & $38(40.0)$ \\
\hline & trace & $8(8.4)$ \\
\hline & living with parents & $47(49.5)$ \\
\hline & others & $2(2.1)$ \\
\hline \multirow{6}{*}{ Motivation of admission } & high school score & $4(4.2)$ \\
\hline & $\begin{array}{c}\text { recommendation of parents or } \\
\text { surrounding }\end{array}$ & $19(20.0)$ \\
\hline & high employment guarantee & $34(35.8)$ \\
\hline & aptitude and interest & $27(28.4)$ \\
\hline & profession & $8(8.4)$ \\
\hline & others & $3(3.2)$ \\
\hline
\end{tabular}

\subsection{Level of college life adjustment, self-esteem, major satisfaction, and social support}

A level of college life adjustment, self-esteem, major satisfaction, and social support was shown in [Table 2]. The mean score for college life adjustment was $3.45 \pm 0.45$, self-esteem was $3.61 \pm 0.48$, major satisfaction was $3.85 \pm 0.48$, and social support was $3.95 \pm 0.55$. 
A Study on Relationships Among Self-esteem, Major Satisfaction, Social Support and College Life Adjustment of Nursing Students

Table 2. College life adjustment, self-esteem, major satisfaction, social support $(\mathrm{N}=95)$

\begin{tabular}{|c|c|c|}
\hline Variables & $\mathrm{M} \pm \mathrm{SD}$ & Range \\
\hline College life adjustment & $3.45 \pm 0.45$ & $1-5$ \\
\hline Self-esteem & $3.61 \pm 0.48$ & $1-4$ \\
\hline Major satisfaction & $3.85 \pm 0.48$ & $1-5$ \\
\hline Social support & $3.95 \pm 0.55$ & $1-5$ \\
\hline
\end{tabular}

\subsection{Differences in college life adjustment by general characteristics}

Table 3. Differences in college life adjustment by general characteristics of subjects $(\mathrm{N}=95)$

\begin{tabular}{|c|c|c|c|}
\hline \multirow{2}{*}{ Characteristics } & \multirow{2}{*}{ Categories } & \multicolumn{2}{|c|}{ College Life Adjustment } \\
\hline & & $\mathrm{M} \pm \mathrm{SD}$ & $\mathrm{t} / \mathrm{F}(\mathrm{p})$ \\
\hline \multirow{2}{*}{ Gender } & male & $3.71 \pm 0.43$ & \multirow{2}{*}{$3.10(.003)$} \\
\hline & female & $3.38 \pm 0.43$ & \\
\hline \multirow{4}{*}{ Religion } & Christian & $3.57 \pm 0.35$ & \multirow{4}{*}{$0.49(.691)$} \\
\hline & catholic & $3.45 \pm 0.67$ & \\
\hline & Buddhism & $3.51 \pm 0.39$ & \\
\hline & no religion & $3.42 \pm 0.47$ & \\
\hline \multirow{5}{*}{ Health state } & very good & $3.59 \pm 0.52$ & \multirow{5}{*}{$1.283(.283)$} \\
\hline & good & $3.48 \pm 0.38$ & \\
\hline & moderate & $3.33 \pm 0.46$ & \\
\hline & bad & $3.25 \pm 0.45$ & \\
\hline & very bad & $3.60 \pm 0.85$ & \\
\hline \multirow{4}{*}{ Economic state } & very high & $3.71 \pm 0.46$ & \multirow{4}{*}{$1.327(.271)$} \\
\hline & high & $3.50 \pm 0.39$ & \\
\hline & medium & $3.39 \pm 0.43$ & \\
\hline & low & $3.42 \pm 0.55$ & \\
\hline \multirow{4}{*}{ Residential type } & dormitory & $3.41 \pm 0.51$ & \multirow{4}{*}{$4.335(.007)$} \\
\hline & trace & $3.97 \pm 0.42$ & \\
\hline & living with parents & $3.40 \pm 0.36$ & \\
\hline & others & $3.41 \pm 0.42$ & \\
\hline \multirow{6}{*}{$\begin{array}{l}\text { The motivation for } \\
\text { admission }\end{array}$} & high school score & $3.26 \pm 0.76$ & \multirow{6}{*}{$1.821(.117)$} \\
\hline & recommendation of parents or surrounding & $3.54 \pm 0.47$ & \\
\hline & high employment guarantee & $3.33 \pm 0.42$ & \\
\hline & aptitude and interest & $3.49 \pm 0.39$ & \\
\hline & profession & $3.57 \pm 0.36$ & \\
\hline & others & $3.96 \pm 0.59$ & \\
\hline
\end{tabular}


Differences in college life adjustment by general characteristics were shown in [Table 3]. College life adjustment was significantly different in gender $(\mathrm{t}=3.10, p=.003)$, and residential type $(\mathrm{F}=4.34, p=.007)$.

\subsection{Correlations among college life adjustment, self-esteem, major satisfaction, and social support}

The correlation between college life adjustment, self-esteem, major satisfaction, and social support was shown in [Table 4]. College life adjustment had a significant positive correlation with self-esteem $(\mathrm{r}=.661, p<.001)$, Major Satisfaction $(\mathrm{r}=.619, p<.001)$, and Social Support $(\mathrm{r}=.513, p<.001)$.

Table 4. Correlations among college life adjustment, self-esteem, major satisfaction, and social support $(\mathrm{N}=95)$

\begin{tabular}{|c|c|c|c|}
\hline \multirow{2}{*}{ Variables } & Self-esteem & $\begin{array}{c}\text { Major } \\
\text { Satisfaction }\end{array}$ & Social Support \\
\cline { 2 - 4 } & $\mathrm{r}(\mathrm{p})$ & $\mathrm{r}(\mathrm{p})$ & $\mathrm{r}(\mathrm{p})$ \\
\hline Major Satisfaction & $.442(<.001)$ & 1 & - \\
\hline Social Support & $.525(<.001)$ & $.476(<.001)$ & 1 \\
\hline College Life Adjustment & $.661(<.001)$ & $.619(<.001)$ & $.513(<.001)$ \\
\hline
\end{tabular}

\section{Conclusion}

This study is a descriptive research study to investigate the relationships among college life adjustment and self-esteem, major satisfaction, and social support of 1st-grade students of nursing college. The results of the study showed that the level of university life adjustment was $3.45 \pm 0.45$ and that higher self-esteem, major satisfaction, and social support are likely to result in a higher degree of college life adjustment. These results suggest that it is necessary to develop a multi-functional intervention program that reflects these variables to improve the adjustment of college students to nursing college.

This study has a limitation in the generalization of the results because the subjects were recruited only from a college, Further studies are needed to expand the range of subjects and scope of the study. it is suggested, in addition, that further studies are needed by adding various variables, to clarify the factors influencing the college life adjustment college life of 1st-grade students in nursing college.

\section{References}

[1] H. Park, M. Kim, and D. Jung, "The effect of stress, social support and self-efficacy on the mental health of female undergraduate students," Journal of Korean Academy Fundamentals of Nursing, vol.15, no.4, pp.513521, (2018)

[2] B. A. Al-khatib, H. S. Awarmleh, and F. S. Samawi, "Student's adjustment to college life at albalqa applied for university," American International Journal of Contemporary Research, vol.11, no.2, pp.7-16, (2011)

[3] H. W. Kang, K. O. Hong, "The influence of college students' problem-solving appraisal and their college credits to career decision level and career preparation behavior," Korea Higher Vocational Education Association, vol.11, no.1, pp.11-20, (2010) 
[4] M. J. Park, Y. L. Ham, and D. N. Oh, "Levels and their correlations of decision-making-competency, adjustment to college life, satisfaction to college life in freshmen," The Korea Contents Society, vol.12, no.4, pp.327-337, (2012)

[5] I. O. Moon and G. W. Lee, "The effect of satisfaction in major and career search efficacy on career search behavior in nursing students," The Journal of Korean Academic Society of Nursing Education, vol.16, no.1, pp.83-91, (2010)

[6] S. Y. Yun and S.H. Min, "Influence of ego-resilience and spiritual well-being on college adjustment in the major of nursing student," Journal of Digital Convergence, vol.12, no.12, pp.395-403, (2014)

[7] H. S. Park and K. S. Jeong, "Influence of self-directed learning ability and creativity on college adjustment in nursing students," The Journal of Korean Academic Society of Nursing Education, vol.19, no.4, pp.549-557, (2013)

[8] K. M. Lim and J. H. Park, "The effects of nursing students' major satisfaction and professor-student interaction on their adjustment to university life," Journal of the Korea Academia-Industrial Cooperation Society, vol.19, no.9, pp.195-205, (2018)

[9] Y. H. Choi and M. J. Chae, "Factors associated with college life adjustment of nursing students," Asia Pacific Journal of Multimedia Services Convergent with Art, Humanities, and Sociology, vol.8, no.8, pp. 419-432, (2018)

[10] J. H. Oh, "The influencing factors of self-esteem and major satisfaction on college adjustment among nursing students," The Korea Contents Society, vol.14, no.10, pp.873-884, (2014)

[11] S. Y. Park, "Development and validation of the college life adjustment instrument for nursing student," Ph. D. dissertation, Dankook University, pp.1-137, (2016)

[12] Rosenberg M., "Society and adolescent self-image," Princeton, NJ: Princeton University Press, (1965)

[13] B. J. Jon, "Self-esteem: A test of its measurability,” Journal of Yonsei University, vol.11, no.1, pp.107-130

[14] H. S. Ha, "A study of department satisfaction and school satisfaction of undergraduate students," M.S. thesis, Seoul National University, pp.1-97, (1999)

[15] D. J. Lee, "The relationships among satisfaction in major, gender identity, and gender stereotypes of male nursing students," M.S. thesis, Yonsei University, pp.1-68, (2004)

[16] J. W. Park, “A study to develop a scale f social support,” Ph. D. dissertation, Yonsei University, pp.1-150

[17] Y. S. Kim, "Study on the relationship between life satisfaction and perceived social support among adults with mental disorders," M.S. thesis, Ewha Womans University, pp.1-96, (1995) 